Çukurova Üniversitesi Mühendislik Mimarlık Fakültesi Dergisi, 34(3), ss. 219-233, Eylül 2019

Çukurova University Journal of the Faculty of Engineering and Architecture, 34(3), pp. 219-233, September 2019

\title{
Kitosan-Vişne Çekirdeği Kabuğu Pirolitik Çarı Kompozit Boncuklarının Sentezi ve Karakterizasyonu: Cr(VI) Gideriminde Kullanılması
}

\author{
Türkan ALTUN¹, Hüseyin ECEVIT ${ }^{* 1}$ \\ ${ }^{1}$ Konya Teknik Üniversitesi, Mühendislik ve Doğa Bilimleri Fakültesi, Kimya Mühendisliği \\ Bölümü, Konya
}

$\ddot{\mathbf{O} z}$

Geliş tarihi: 16.01 .2019

Kabul tarihi: 30.09 .2019

Bu çalışmada, vişne çekirdeği kabuğu pirolitik çarı (VÇKÇ) elde edilmiş ve bu pirolitik çarın kitosanla karıştııılarak boncukların oluşturulması yoluyla kitosan/pirolitik çar kompozit boncukları (K-VÇKÇ) sentezlenmiştir. Sonrasında VÇKÇ ve K-VÇKÇ boncuklarının sulu çözeltilerden $\mathrm{Cr}(\mathrm{VI})$ adsorpsiyonları karşılaştırmalı olarak incelenmiştir. Kesikli adsorpsiyon deneyleri sonucunda; $\mathrm{Cr}(\mathrm{VI})$ giderimi için optimum adsorban miktarı VÇKÇ için $5 \mathrm{~g} / \mathrm{L}, \mathrm{K}-\mathrm{VÇKÇ} \mathrm{için} \mathrm{ise} \mathrm{1,5} \mathrm{g/L;} \mathrm{optimum} \mathrm{pH} \mathrm{VÇKÇ} \mathrm{için} \mathrm{1,56,}$ $\mathrm{K}-\mathrm{VÇKÇ} \mathrm{için} \mathrm{2,} \mathrm{optimum} \mathrm{temas} \mathrm{süresi} 120 \mathrm{dk}$ olarak belirlenmiştir. VÇKÇ ve K-VÇKÇ adsorbanları için adsorpsiyona, Langmuir İzoterm modelinin en uygun model olduğu görülmüştür. Bu izotermden, maksimum adsorpsiyon kapasiteleri VÇKÇ için 14,455 mg/g ve K-VÇKÇ için 86,298 mg/g olarak hesaplanmıştır. Termodinamik hesaplamalar, adsorpsiyonun endotermik ve istemli olduğunu göstermiştir. Adsorpsiyon kinetiği üzerine yapılan hesaplamalar sonucunda adsorpsiyonun yalancı ikinci mertebeden kinetik model ile uyumlu olduğu görülmüştür. Sentezlenen adsorbanların karakterizasyonu SEM/EDX, BET, FTIR ve elementel analiz ile gerçekleştirilmiștir. SEM/EDX ve FTIR analizleri ile Cr(VI)'nın adsorplandığı kanıtlanmıştır. Bu çalışma, VÇKÇ ve K-VÇKÇ’nin sulu çözeltilerden Cr(VI) gideriminde düşük maliyetli ve etkili bir adsorban olabileceğini göstermiştir.

Anahtar Kelimeler: Adsorpsiyon, Cr(VI), Çar, Vişne çekirdeği kabuğu, Kitosan

\section{Syntesis and Characterization of Chitosan-Cherry Kernel Shell Pyrolytic Charcoal Composite Beads: Using at the Cr(VI) Removal}

\begin{abstract}
In this study, cherry kernel shell pyrolytic charcoal (CKSC) was obtained and chitosan/pyrolitic charcoal (C-CKSC) composite beads were synthesized by mixing this pyrolytic charcoal with chitosan and forming beads. Then, $\mathrm{Cr}(\mathrm{VI})$ adsorption of CKSC and C-CKSC beads from aqueous solutions has been studied comparatively. As a result of batch adsorption experiments; the optimum adsorbent amounts for $\mathrm{Cr}(\mathrm{VI})$ adsorption are $5 \mathrm{~g} / \mathrm{L}$ for CKSC and $1.5 \mathrm{~g} / \mathrm{L}$ for $\mathrm{C}-\mathrm{CKSC}$; optimum $\mathrm{pHs}$ are 1.56 and 2 for CKSC and C-CKSC respectively; optimum contact time is 120 minutes. The adsorption equilibrium data fitted well with Langmuir isotherm model for CKSC and C-CKSC adsorbents. The maximum adsorption capacities from this isotherm model were calculated as $14.455 \mathrm{mg} / \mathrm{g}$ for CKSC and $86.298 \mathrm{mg} / \mathrm{g}$ for C-CKSC. Thermodynamic calculations have shown that the adsorption is endothermic and has
\end{abstract}

*Sorumlu yazar (Corresponding author): Hüseyin ECEVIT, huseyin.ecevit@hotmail.com 
spontaneous nature. As a result of calculations on the adsorption kinetics, adsorption was found to be consistent with the pseudo second order kinetic model. Characterizations of the synthesized adsorbents were performed by SEM/EDX, BET, FTIR and elemental analysis. SEM/EDX and FTIR analysis proved that $\mathrm{Cr}$ (VI) was adsorbed. This study has shown that CKSC and C-CKSC can be effective adsorbents at low cost for $\mathrm{Cr}(\mathrm{VI})$ removal from aqueous solutions.

Keywords: Adsorption, Cr(VI), Charcoal, Cherry kernel shell, Chitosan

\section{GíRiş̧}

Ağır metallerin varlığı belirli sınırların üzerindeki miktarlarda bulunursa canlıların sağlığı açısından olumsuz etkilere ve ölümlere sebep olur. Canlı yaşamına etki edecek şekilde, ağır metallerin doğaya karışmasının beşeri sebepleri (madencilik, döküm, elektrokaplama, boyama gibi) ve doğal sebepleri (Volkanik faaliyetler, mineral ve kayaçların ayrışması ve erozyonu gibi) vardır. Günümüzde sanayileşmenin artması sebebiyle beşeri kaynaklardan doğaya salınarak canlılara nüfuz eden ağır metallerin miktarı artmaktadır. $\mathrm{Bu}$ sebeple ağır metal derişimlerinin belirlenen sınırların altına düşürülmesi insan ve tüm canlıların sağlığını korumak için önemlidir [1].

$\mathrm{Bu}$ ağır metallerin arasındaki krom, doğada üç ve altı değerlikli katyonlar halinde $\mathrm{Cr}$ (III) ve $\mathrm{Cr}(\mathrm{VI})$ formlarında bulunmaktadır. Kromun en yaygın kullanıldığı alanların başında paslanmaz çelik üretimi, deri sanayi ve kaplama/elektrokaplama sanayi gelir [2]. Dündar ve arkadaşları [2] deri, tekstil, kaplama ve otomotiv yan sanayi atık sularının ağır metal derişimlerini belirledikleri çalışmada toplam krom derişimlerinin; deri sanayi kuruluşunun atık suyunda $1,23 \mathrm{mg} / \mathrm{L}$, tekstil sanayi kuruluşunun atık suyunda $0,19 \mathrm{mg} / \mathrm{L}$, kaplama sanayi kuruluşunun atık suyunda 72,61 mg/L, otomotiv yan sanayi kuruluşunun atık suyunda $0,27 \mathrm{mg} / \mathrm{L}$ olduğunu raporlamışlardır. Canlı ve arkadaşları [3] deri sanayi kuruluşunun atık suyundan aldıkları numunenin $\mathrm{Cr}(\mathrm{VI})$ derişiminin 7,50 mg/L, toplam krom derişiminin ise 7,78 mg/L olduğunu, ayrıca tekstil boyalarının da en az $500 \mathrm{mg} / \mathrm{kg}$ serbest krom içerdiğini raporlamışlardır. Bu değerler canlıların sağlığı için belirlenmiş sınır değerlerin oldukça üzerindedir. Yüksek krom derişimlerine sahip olan atık suların alıcı ortama deşarj edilmeden önce mutlaka krom giderimi işlemlerinden geçirilmeleri ve içerdikleri kromun sınır değerlerin altına düşürülmesinin sağlanması gerekmektedir. Krom elementinin $\mathrm{Cr}(\mathrm{VI})$ formu $\mathrm{Cr}$ (III) formuna göre çok daha toksik bir bileşendir ve toprak ve sucul ortamlardan kolaylıkla hareket ederek cilde nüfuz edebilir.

Cr(III) özellikle glukoz metabolizması için olmak üzere insan sağlığı açısından gereklidir. Buna karşın $\mathrm{Cr}(\mathrm{VI})$ oldukça toksik, tahriş edici ve kanserojendir. $\mathrm{Cr}(\mathrm{VI})$ biyolojik olarak parçalanamaz ve canlı vücudunda birikir [4,5]. Cr(VI)'nın zararlı etkilerinden insan ve diğer canlıların korunabilmesi için içilebilir sulardaki $\mathrm{Cr}(\mathrm{VI})$ derişimi en fazla $0,05 \mathrm{mg} / \mathrm{L}$ olmalıdır [4].

Sulu çözeltilerden ağır metallerin giderilmesinde uygulanan yöntemler arasında adsorpsiyon, iyon değişimi, membran filtrasyon, kimyasal çöktürme yöntemleri sayılabilir. $\mathrm{Bu}$ metotların arasında adsorpsiyon, $\mathrm{Cr}(\mathrm{VI})$ giderimi için etkili bir yöntemdir. Ayrıca adsorpsiyon, düşük maliyetli adsorbanlar kullanıldığında, diğer yöntemlerden daha ekonomik bir yöntemdir [6].

Adsorpsiyon, bir katı adsorban yüzeyinde akışkan fazda bulunan bazı bileşen ya da bileşenlerin (adsorbat) tutunarak ayrılması işlemidir. Adsorbanlar akışkan fazda çözünmeme, ekonomik olma, geri dönüştürülebilme, kolay elde edilebilme, ayrılması istenen bileşeni adsorplama kapasitesi yüksek olma gibi özelliklere sahip olmalidir [7].

Son dönemde sudan ağır metallerin giderilmesi için düşük maliyetli adsorbanların kullanılması üzerine bilimsel çalışmalar yoğunlaşmıştır. Bu düşük maliyetli adsorbanlar genellikle tarımsal ve endüstriyel süreçlerden veya gıda üretimi süreçlerinden bol miktarda elde edilen atık ürünlerdir [8]. Bazı atık ürünler adsorban olarak doğrudan kullanılabilirken, bazılarının adsorpsiyon 
performanslarının arttırılması için aktifleştirme, pirolitik çar ya da aktif karbon haline getirme gibi muamelelerden geçirilmesi ya da kompozitlerinin oluşturulması gerekli olmaktadır.

$\mathrm{Bu}$ çalışmada $\mathrm{Cr}(\mathrm{VI})$ adsorpsiyonunda kullanılan pirolitik çarın hammaddesi olan vişne çekirdeği, vişne meyvesinin ağırlığının \%14,6'sını oluşturan tarımsal bir atıktır. Vişne meyvesi Türkiye'de oldukça fazla üretilen bir üründür. Türkiye'de 2017 y1lında toplam vişne üretimi 181.874 ton'dur [9]. Bu yüzden vişnenin işlenmesi sırasında yüksek miktarda vişne çekirdeği atık olarak ortaya çıkmaktadır [10]. Vişne çekirdeğinden üretilen pirolitik çarın adsorban olarak kullanımı sağlanabilirse ekonomik bir değer kazanarak katma değer sağlayacaktır.

Vişne çekirdeği kabuğunun Cr(VI) adsorpsiyonunda kullanımı ile ilgili Altun [11] tarafindan yapılan çalışmada vişne çekirdeği kabuğunun iyi derecede $\mathrm{Cr}(\mathrm{VI})$ adsorplama kapasitesine sahip olduğu belirtilmiştir (Cr(VI) adsorpsiyon kapasiteleri: ham halde $13,57 \mathrm{mg} / \mathrm{g}$, kitosan kaplı halde 24,492 mg/g). Bu çalışma kapsamında da vişne çekirdeği kabuğunun sahip olduğu adsorpsiyon kapasitesinin geliştirilmesi amaçlanmıştır.

Vişne çekirdeği gibi biyolojik kökenli maddelerden pirolitik çar elde edilebilir. Pirolitik çar, organik malzemenin pirolizi sonrasında kalan karbon oranı yüksek katı kalıntıdır [12]. Pirolitik çar üretiminde hammadde herhangi bir kimyasal katkı maddesi ile muamele edilmez. Yalnızca 400-1000 ${ }^{\circ} \mathrm{C}$ sıcaklıklarında piroliz işlemine tabi tutulan hammaddenin içerisindeki uçucu maddeler uzaklaştırılmış, karbon oranı, yüzey alanı ve gözenekliliği arttırılmış olur. $\mathrm{Bu}$ sayede bazı malzemelerin adsorpsiyon performans1 artırılabilmektedir [7,13].

Kitosan, adsorpsiyon uygulamalarında tek başına adsorban olarak kullanılabilmesinin yanında, çeşitli malzemelerle oluşturulan kompozitlerde matris görevi üstlenerek malzemelerin mekanik ve adsorpsiyon özelliklerini iyileştiren bir madde olarak kullanılmaktadır. Kitosan, doğada selülozdan sonra en fazla bulunan biyopolimer olan kitinin deasetilasyonu ile elde edilir $[14,15]$. Deasetilasyon reaksiyonu Nomanbhay ve Palanisamy [4] tarafından yapılan çalışmada sunulmuştur.

Kitosanın yapısında bulunan reaktif amino grupları düşük pH'larda protonlanarak anyonik boyalar ve metal anyonları ile elektrostatik etkileşime girerler. $\mathrm{Bu}$ sebeple kitosan atıksulardan metal anyonların giderilmesinde etkili olmaktadır $[14,16]$.

Bu çalışmada da vişne çekirdeği kabuğundan elde edilmiş olan pirolitik çarın (VÇKÇ) ve bu pirolitik çar ile kitosandan elde edilen kompozit boncukların (K-VÇKÇ) sulu çözeltilerden Cr(VI)'nın adsorpsiyon ile giderimindeki verimlilikleri araştırılmıştır.

\section{MATERYAL VE METOT}

\subsection{Materyal}

Yapılan laboratuvar çalışmalarında vişne çekirdeği kırılıp içindeki yağlı çekirdek ayrılmıştır. Kalan kabuk azot atmosferinde piroliz işleminden geçirilerek pirolitik çar haline getirilmiştir. Piroliz şartları şu şekildedir: $25^{\circ} \mathrm{C}$ başlangıç sıcaklığı, $10{ }^{\circ} \mathrm{C} / \mathrm{dk}$ 1sıtma hızı, $500{ }^{\circ} \mathrm{C}$ piroliz sicaklığ 1 ve 30 dakika alıkonma süresi. Bu yolla elde edilen pirolitik çar (VÇKÇ) adsorban olarak kullanılmıştır. Diğer kimyasal malzemelerden kitosan ve kitosanın çapraz bağlanmasında kullanılan glutaraldehit Sigma Aldrich firmasindan; potasyum dikromat, asetik asit, sodyum hidroksit, hidroklorik asit ve etanol Merck firmasından temin edilmiştir.

\subsection{Adsorbanların Hazırlanması}

VÇKÇ Retsch RM 100 model öğütücü ile ögütülüp elenmiş ve tanecik boyutu $125 \mu \mathrm{m}$ altına düşürülmüştür. Pirolitik çar-kitosan kompozit boncuklarının (K-VÇKÇ) hazırlanmasında, $3 \mathrm{~g}$ kitosan $150 \mathrm{~mL} \% 3$ 'lük asetik asit çözeltisine eklenerek 24 saat karıştırıldı. Bu karışıma 1,5 g pirolitik çar ilave edilerek 2 saat daha karıştırıldı. Elde edilen sıvı karışım 3 M $250 \mathrm{~mL} \mathrm{NaOH}$ çözeltisine damlatılarak boncuk oluşumu sağlandı. Boncuklar, sertleşmeleri için bir gece çözelti 
içerisinde bekletildi ve sonra çözeltiden ayrılarak pH'sı 7 olana kadar yıkandı. Yıkanan boncuklar $30 \mathrm{~mL}$ etanol ve $0,3 \mathrm{~mL}$ glutaraldehit içeren çözelti içerisinde $70{ }^{\circ} \mathrm{C}$ 'de 5 saat karıştırılarak boncukların glutaraldehit ile çapraz bağlanması sağlandı. Şahin [16] tarafindan yapılan çalışmada kitosanın glutaraldehit ile çapraz bağlanma reaksiyonu sunulmuştur. Çapraz bağlanan boncuklar süzülüp önce etkileşmemiş glutaraldehitin uzaklaştırılması için etanol ile y1kand1, daha sonra pH's1 7 olana kadar ultra saf su ile yıkandı ve oda sıcaklığında 24 saatte kurutuldu [17].

\subsection{Adsorbanların Karakterizasyonları}

VÇKÇ ve K-VÇKÇ'nin elementel analiz (LECO CHNS-932), FTIR (Nicolet 380, 4000-550 $\mathrm{cm}^{-1}$ dalga boyu aralığında), SEM/EDX (Hitachi-SU 1510) ve BET yüzey alanı (QuantachromeQuadrasorb Evo 4) analizleri ile karakterizasyonları yapılmıştır. Pirolitik çar ve kompozit boncuk adsorbanlarının elementel analizi Orta Doğu Teknik Üniversitesi Merkez Laboratuvarında, SEM/EDX ve BET analizleri ise Necmettin Erbakan Üniversitesi Bilim ve Teknoloji Araştırma ve Uygulama Merkezi'nde gerçekleştirilmiştir.

\subsection{Kesikli Adsorpsiyon Çalışmaları}

Adsorpsiyon için optimum şartların belirlenmesi için sırasıyla adsorban miktarı, başlangıç $\mathrm{Cr}(\mathrm{VI})$ derişimi, temas süresi, $\mathrm{pH}$ ve sıcaklık parametreleri değiştirilerek adsorpsiyon denemeleri kesikli olarak yapılmıştır. Kullanılacak olan $\mathrm{Cr}(\mathrm{VI})$ çözeltileri $\mathrm{K}_{2} \mathrm{Cr}_{2} \mathrm{O}_{7}$ 'n ultra saf suda çözdürülmesi ile hazırlanmıştır. Hazırlanan çözeltilerden adsorpsiyon denemeleri için 10 'ar $\mathrm{mL}$ ölçülerek adsorbanlar ile karıştırılmıştır. Çözelti pH'larının ayarlanmasinda $0,1 \mathrm{M} \mathrm{HCl}$ ile $0,1 \mathrm{M} \mathrm{NaOH}$ çözeltileri ve GLP $22 \mathrm{pH}$ ölçüm cihazı kullanılmıştır. Adsorpsiyonun ardından çözeltiler, mavi bant süzgeç kağıdı kullanılarak adsorbandan uzaklaştırılmış ve çözeltilerdeki $\mathrm{Cr}(\mathrm{VI})$ derişimi UV-Visible spektrometre (Shimadzu UV-1700) ile ölçülmüştür. Her parametre çalışmasında elde edilen optimum sonuç bir sonraki parametre çalışmasında kullanılmıştır.
Birim adsorban kütlesi başına uzaklaş̧ırılan $\mathrm{Cr}(\mathrm{VI})$ miktarı ( $\mathrm{q}_{\mathrm{e}}$ ) Eşitlik 1 kullanılarak, adsorpsiyon yüzdesi ise Eşitlik 2 kullanılarak hesaplanmıştır.

$q_{e}=\frac{\left(C_{0}-C_{e}\right) V}{w}$

$\%$ adsorpsiyon $=\frac{\mathrm{C}_{0}-\mathrm{C}_{\mathrm{e}}}{\mathrm{C}_{0}} \times 100$

Burada; $\mathrm{C}_{0}$ çözeltideki başlangıç $\mathrm{Cr}(\mathrm{VI})$ derişimini $(\mathrm{mg} / \mathrm{L}), \quad \mathrm{C}_{\mathrm{e}}$ adsorbanla çözeltinin temas süresi sonunda çözeltide kalan $\mathrm{Cr}(\mathrm{VI})$ derişimini $(\mathrm{mg} / \mathrm{L})$, V çözelti hacmini (L) ve w adsorban miktarını (g) ifade etmektedir.

\section{4. İzoterm Çalışmaları}

Başlangıç $\mathrm{Cr}(\mathrm{VI})$ derişimi çalışmasından elde edilen veriler Langmuir, Freundlich, Scatchard, Dubinin-Radushkevich ve Temkin izotermlerine uygulandı. $\mathrm{Bu}$ izotermlerin eşitlikleri sırasıyla Eşitlik 3-7'de verilmiştir.

$\frac{C_{e}}{q_{e}}=\frac{C_{e}}{A_{s}}+\frac{1}{A_{s} K_{b}}$

$\log q_{e}=\log K_{F}+\frac{1}{n} \log C_{e}$

$\frac{\mathrm{q}_{\mathrm{e}}}{\mathrm{C}_{\mathrm{e}}}=\mathrm{Q}_{\mathrm{s}} \mathrm{K}_{\mathrm{s}}-\mathrm{q}_{\mathrm{e}} \mathrm{K}_{\mathrm{s}}$

$\ln \mathrm{q}_{\mathrm{e}}=\ln \mathrm{X}_{\mathrm{m}}-\mathrm{K} \varepsilon^{2}$

$\mathrm{q}_{\mathrm{e}}=\frac{\mathrm{RT}}{\mathrm{b}} \ln \mathrm{A}_{\mathrm{T}}+\frac{\mathrm{RT}}{\mathrm{b}} \ln \mathrm{C}_{\mathrm{e}}$

Burada; Langmuir eşitliğindeki $A_{s}$ yüzeyde tam bir tek tabaka oluşturmak için adsorbanın birim kütlesinde adsorplanan madde miktarını, $\mathrm{K}_{\mathrm{b}}$ adsorpsiyon enerjisi ile ilgili bir sabiti ifade eder. Freundlich eşitliğindeki $\mathrm{K}_{\mathrm{F}}$ adsorpsiyon kapasitesini, $\mathrm{n}$ izoterm sabitini ifade eder. Scatchard eşitliğindeki $K_{s}$ bağlanma sabiti ve $Q_{s}$ maksimum adsorpsiyon kapasitesidir. D-R eşitliğindeki $\mathrm{X}_{\mathrm{m}}$ adsorbanın maksimum adsorpsiyon kapasitesini, $\mathrm{K}$ adsorpsiyon enerjisi sabitini ve $\varepsilon$ ise polanyi potansiyelini ifade eder. Temkin eşitliğindeki $\mathrm{b}$ adsorpsiyon isısı ile alakalı 
Temkin sabitini, $A_{T}$ Temkin izoterm sabitini, $R$ evrensel gaz sabitini ve $\mathrm{T}$ sicaklığ 1 ifade eder. $\mathrm{Bu}$ parametreler, izotermlerin lineer eşitliklerinden elde edilen izoterm grafiklerinin kesim noktasından ve eğiminden hesaplanmıştır.

Eşitlik 6'da verilen D-R izoterm eşitliğindeki $\varepsilon$ (polanyi sabiti) Eşitlik 8 ile hesaplanabilir. Ayrıca yine D-R izoterm eşitliğindeki $\mathrm{K}$ değeri kullanılarak adsorpsiyon enerjisi (E) değeri Eşitlik 9 ile hesaplanmıştır.

$\varepsilon=\mathrm{RT} \ln \left(1+\frac{1}{\mathrm{C}_{\mathrm{e}}}\right)$

$E=(2 K)^{-1 / 2}$

Eşitlik 8'deki $\mathrm{R}$ evrensel gaz sabitini ve $\mathrm{T}$ ise sıcaklığı ifade eder.

\subsection{Kinetik Çalışmaları}

Temas süresinin etkisinin belirlenmesi çalışmalarından elde edilen veriler yalancı birinci mertebeden kinetik model (Lagergren kinetik model) ve yalanci ikinci mertebeden kinetik modellerine uygulanarak adsorpsiyon mekanizması aydınlatılmaya çalışıldı. Bu kinetik modellerin doğrusallaştırılmış eşitlikleri sırasıyla Eşitlik 10 ve 11 'de verilmiştir.

$\log \left(q-q_{t}\right)=\log q-\left(\frac{k_{a d} t}{2,303}\right)$

$\frac{\mathrm{t}}{\mathrm{q}_{\mathrm{t}}}=\frac{1}{\mathrm{~h}}+\left(\frac{1}{\mathrm{q}}\right) \mathrm{t}$

Yalancı ikinci mertebeden kinetik model eşitliğinde yer alan $\mathrm{h}$ değeri sorpsiyon başlangıç hızını ifade eder ve Eşitlik 12 ile hesaplanır.

$\mathrm{h}=\mathrm{k}_{2} \mathrm{q}^{2}$

Kinetik model eşitliklerinde; q, denge durumunda adsorbanın birim kütlesi başına adsorpladığı madde miktarını; $\mathrm{q}_{\mathrm{t}}$, herhangi bir $\mathrm{t}$ anında adsorbanın birim kütlesi başına adsorpladığı madde miktarını ve $\mathrm{k}_{\mathrm{ad}}$ ile $\mathrm{k}$ hız sabitlerini ifade etmektedir.

\subsection{Termodinamik Çalışmalar}

Adsorpsiyona sıcaklığın etkisinin belirlenmesi çalışmasından elde edilen veriler kullanılarak adsorpsiyon sırasındaki entalpi değişimi $(\Delta \mathrm{H})$, entropi değişimi $(\Delta S)$ ve Gibbs serbest enerjisinin değişimleri hesaplanmıştır. $\mathrm{Bu}$ termodinamik parametrelerin hesaplanmasında Eşitlik 13 ve 14 kullanılmıştır.

$\log \mathrm{K}_{\mathrm{D}}=\frac{0,434}{\mathrm{R}} \Delta \mathrm{S}-\frac{0,434}{\mathrm{RT}} \Delta \mathrm{H}$

$\Delta \mathrm{G}=\Delta \mathrm{H}-\mathrm{T} \Delta \mathrm{S}$

$\mathrm{Bu}$ eşitliklerde; $\mathrm{K}_{\mathrm{D}}$ termodinamik denge sabitini ifade eder ki Eşitlik 15'teki şekilde hesaplanmaktadir. $\mathrm{R}$ evrensel gaz sabitini, $\mathrm{T}$ ise sıcaklığı ifade eder.

$\mathrm{K}_{\mathrm{D}}=\frac{\mathrm{q}_{\mathrm{e}}(\mathrm{mmol})}{\mathrm{C}_{\mathrm{e}}(\mathrm{mmol})}$

Burada ise; $\mathrm{q}_{\mathrm{e}}$ adsorplanan madde miktarını ve $\mathrm{C}_{\mathrm{e}}$ temas süresi sonunda çözeltide kalan madde miktarını ifade eder.

\section{SONUÇLAR}

\subsection{Adsorbanların Karakterizasyonları}

Adsorpsiyon öncesi VÇKÇ ve K-VÇKÇ ile adsorpsiyon sonrası K-VÇKÇ için FTIR spektrumları Şekil 1'de verilmiştir. Yapılan analizler sonucunda $3600-3750 \mathrm{~cm}^{-1}$ aralığındaki bant O-H gerilmesinden, 3270-3350 $\mathrm{cm}^{-1}$ aralığındaki bant ise $\mathrm{O}-\mathrm{H}$ ve $\mathrm{N}-\mathrm{H}$ gerilmesinden kaynaklanmaktadır $\quad[18-20] . \quad 2850-3021 \quad \mathrm{~cm}^{-1}$ aralığındaki bant alifatik $\mathrm{C}-\mathrm{H}$ gerilmesinden kaynaklanır [20]. 2000-2200 $\mathrm{cm}^{-1}$ aralığındaki bant alkinlerin $-\mathrm{C} \equiv \mathrm{C}$ - üçlü bağından kaynaklanmaktadır [21]. $1540-1570 \mathrm{~cm}^{-1}$ aralığındaki $\mathrm{C}=\mathrm{C}$ titreşim bandı aromatik yapıların varlığına işaret eder [13]. $1403 \mathrm{~cm}^{-1}$ civarlarında görülen bant $-\mathrm{CH},-\mathrm{CH}_{2}$ ve $-\mathrm{CH}_{3}$ fonksiyonel gruplarının deformasyon gerilmesine işaret etmektedir [19]. $730-875 \mathrm{~cm}^{-1}$ aralığındaki bant $\mathrm{C}-\mathrm{H}$ eğilmesine aittir [22]. 
K-VÇKÇ grafiklerinde görülen 1616-1637 $\mathrm{cm}^{-1}$ 'deki bant aromatik halka yapılarının $\mathrm{N}-\mathrm{H}$ eğilmesine aittir [23]. 1360-1375 $\mathrm{cm}^{-1}$ aralığındaki bant alkol grubundaki - $\mathrm{CH}$ titreşimlerine aittir [24]. $1125-1141 \mathrm{~cm}^{-1}$ aralığındaki kitosanın karakteristik bandı glikozidik (C-O-C) bağlarının gerilme titreşimi sebebiyle oluşmuştur [5]. 1041-1051 cm-1 aralığındaki bant kitosan yapısındaki $\mathrm{CH}-\mathrm{OH}$ bağlarının gerilme titreşimine ait banttır [18]. 1022-1024 $\mathrm{cm}^{-1}$ aralığındaki bant ise amino gruplarının $\mathrm{C}-\mathrm{N}$ bağlarının gerilme titreşimlerine aittir [25]. Bu sonuçlar VÇKÇ adsorbanının kitosan ile kompozitinin oluşturulması sonrası yapısında hidroksil, amin vb. fonksiyonel gruplarda artışın meydana geldiğini göstermektedir.
K-VÇKÇ için 3200-3400 $\mathrm{cm}^{-1}$ aralığında görülen bant adsorpsiyon sonrasında oluşmamıştır. $2875-2900 \mathrm{~cm}^{-1}$ aralığında, $1300-1650 \mathrm{~cm}^{-1}$ aralığında, 1020-1060 $\mathrm{cm}^{-1}$ aralığında bantların şiddetlerinde düşüşler görülmektedir. Bunun yanında 1100-1300 aralığında da bantların şiddetlerinde artışlar görülmektedir. 2913, 1637, 1544 ve $1403 \mathrm{~cm}^{-1}$ 'deki bantların şiddetleri azalarak sirasiyla 2893, 1616, 1529 ve $1380 \mathrm{~cm}^{-1}$,e kaymıştır. $2183 \mathrm{~cm}^{-1}$, deki bant ise şiddeti artarak $2150 \mathrm{~cm}^{-1}$ 'e kaymıştır.

Adsorpsiyon sonrasinda C-H, C-N, O-H, N-H yapılarına işaret eden bantlarda meydana gelen bu değişimler Cr(VI)'nın yüzeye tutunmasında bu grupların etkili olduklarına işaret etmektedir [26].

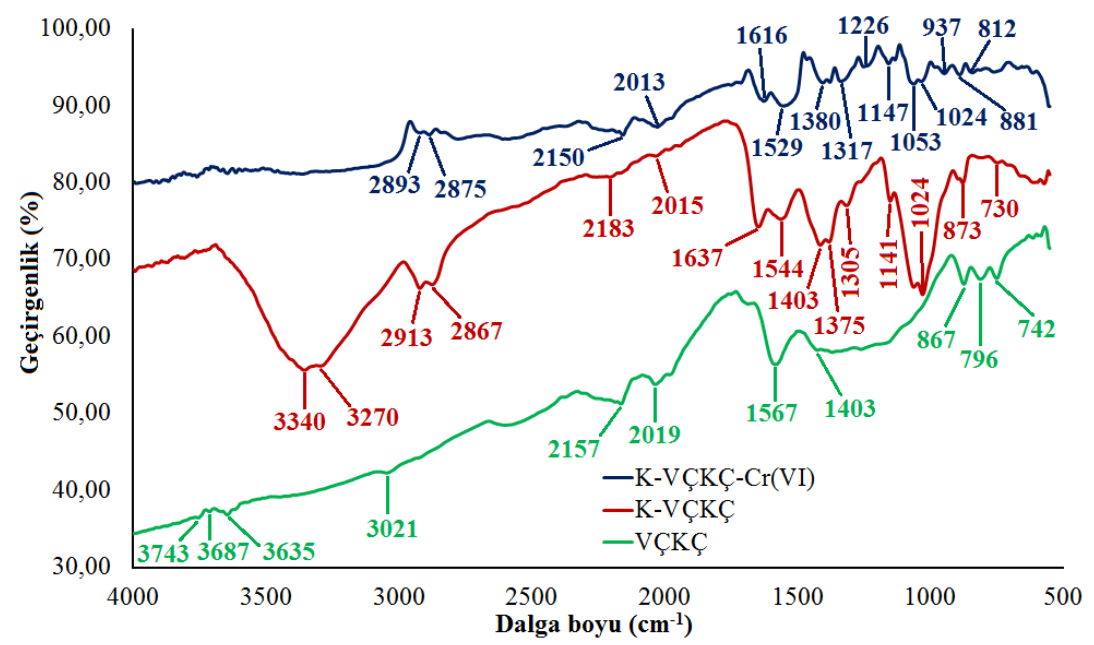

Şekil 1. Vişne çekirdeği kabuğu pirolitik çarının (VÇKÇ), kitosan/pirolitik çar kompozitinin (K-VÇKÇ) ve bu kompozitin $\mathrm{Cr}(\mathrm{VI})$ yüklenmiş halinin FTIR spektrumları

Adsorbanların elementel analiz sonucuna göre pirolitik çarın kitosanla kompozitinin oluşturulması sonrası yapıdaki karbon oranı $\% 85,20$ 'den \%51,66'ya düşmüş, oksijen oranı $\% 10,45$ 'ten $\% 36,94$ 'e, azot oran1 \%1,42'den $\% 5,16$ 'ya, hidrojen oran1 \%2,93'ten \%6,24'e yükselmiştir. Kitosan yapısındaki $-\mathrm{NH}_{2}, \quad-\mathrm{OH}$ gruplarının varlığından dolayı, VÇKÇ'nin kitosanla kaplanması sonrasında fonksiyonel grup miktarı artmıştır. Yapılan elementel analiz sonuçları da bu sonucu desteklemektedir.
Şekil 2'de VÇKÇ ve K-VÇKÇ adsorbanlarının adsorpsiyon öncesi ve sonrasındaki SEM görüntüleri, Şekil 3 ve 4'te de EDX analizi sonuçları verilmiştir.

Şekil 2(a), (b) ve (c)'deki VÇKÇ için adsorpsiyondan önce ve sonraki SEM görüntüleri incelendiği zaman; adsorpsiyondan önce daha düz olan adsorban yüzeyinin $\mathrm{Cr}(\mathrm{VI})$ adsorpsiyonundan sonra dolduğu ve yüzeyde parçacıklı yapı oluştuğu görülmüştür. 
Şekil 2(d) ve (e)'deki K-VÇKÇ adsorbanının SEM görüntülerinde yüzeyin homojen olduğu görülmektedir. Bu da kitosanın yüzeyde homojen dağıldığını göstermektedir. K-VÇKÇ için adsorpsiyondan önceki ve sonraki SEM görüntüleri incelendiğinde; $\mathrm{Cr}(\mathrm{VI})$ yüklemesinden önce yüzeylerde daha küçük parçacıklar varken, $\mathrm{Cr}(\mathrm{VI})$ yüklemesinin ardından yüzeylerde daha iri parçacıkların oluştuğu ve yüzeydeki boşlukların dolduğu görülmektedir. $\mathrm{Bu}$ da adsorbanların yüzeylerinde $\quad \mathrm{Cr}(\mathrm{VI}) \quad$ adsorpsiyonunun gerçekleştiğini desteklemektedir.
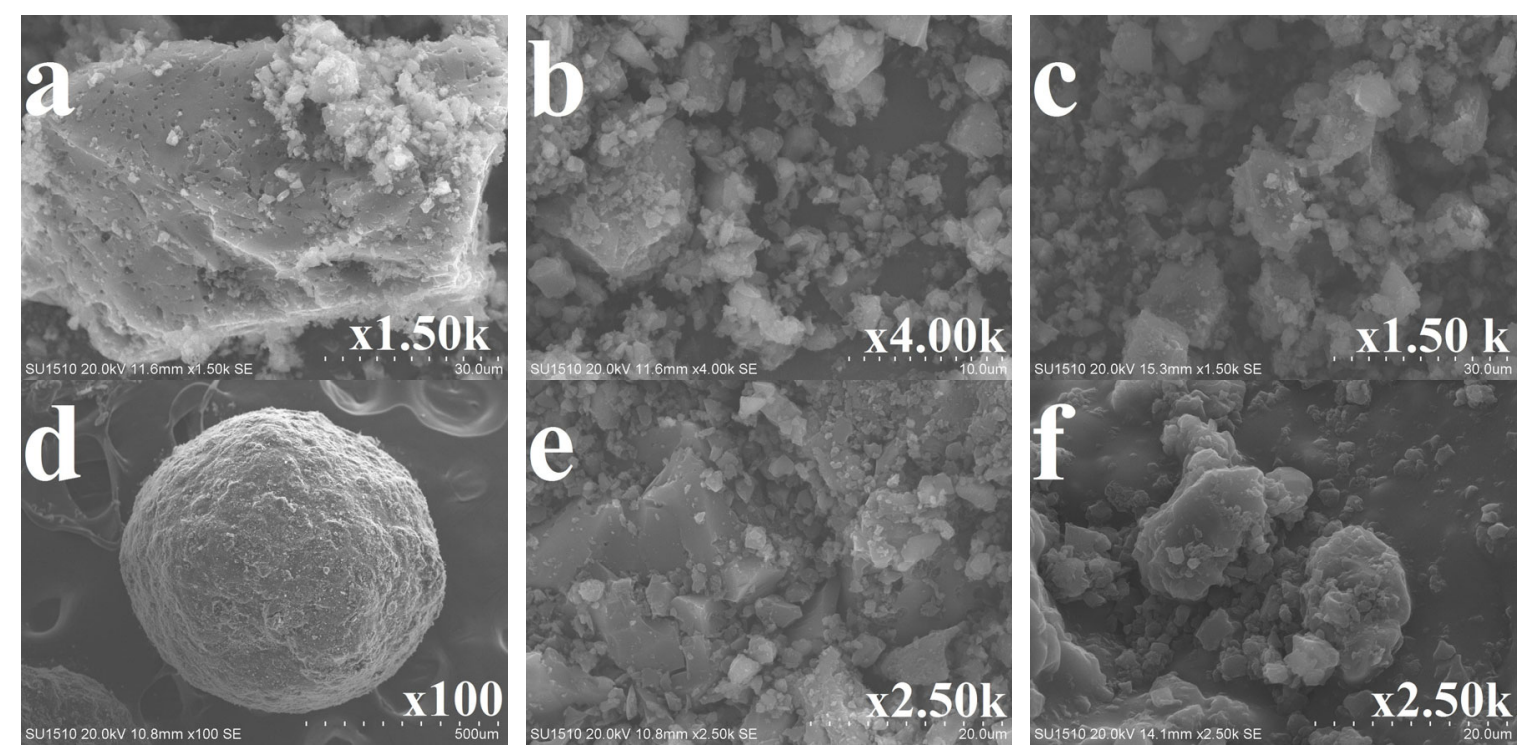

Şekil 2. SEM görüntüleri; (a) ve (b): adsorpsiyon öncesi VÇKÇ, (c): adsorpsiyon sonrası VÇKÇ (d) ve (e): adsorpsiyon öncesi K-VÇKÇ, (f): adsorpsiyon sonrası K-VÇKÇ
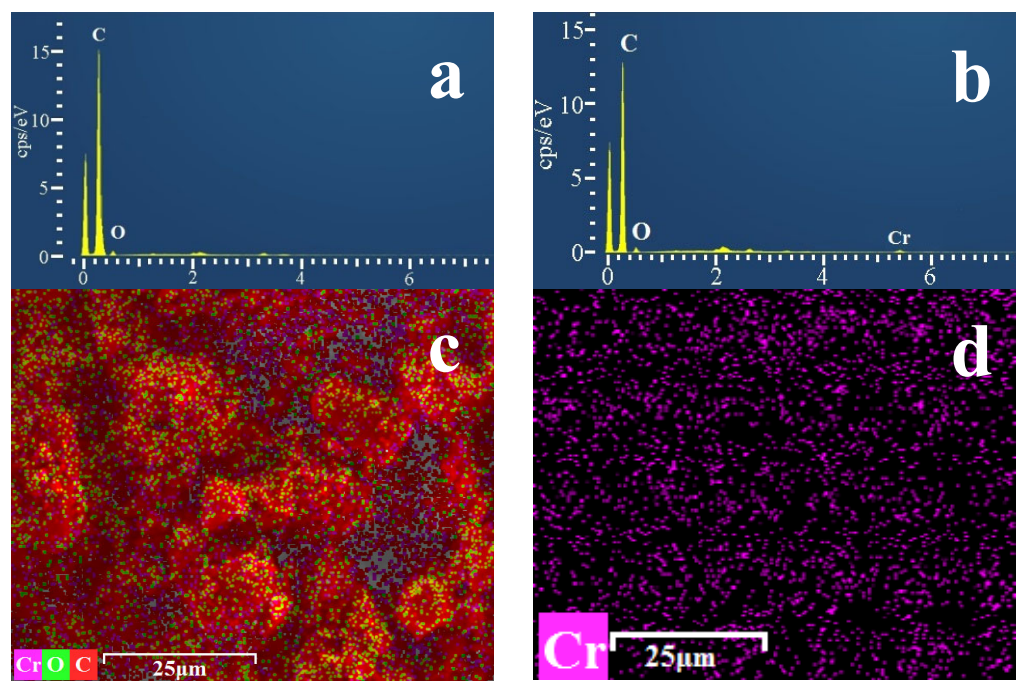

Şekil 3. VÇKÇ için; (a) adsorpsiyon öncesi EDX spektrumu, (b) adsorpsiyon sonrası EDX spektrumu, (c) adsorpsiyon sonrasında elementlerin yüzey üzerindeki dağılım haritası, (d) adsorpsiyon sonrasında $\mathrm{Cr}$ iyonlarının yüzey üzerindeki dağılım haritası 
Kitosan-Vişne Çekirdeği Kabuğu Pirolitik Çarı Kompozit Boncuklarının Sentezi ve Karakterizasyonu: Cr(VI) Gideriminde Kullanılması
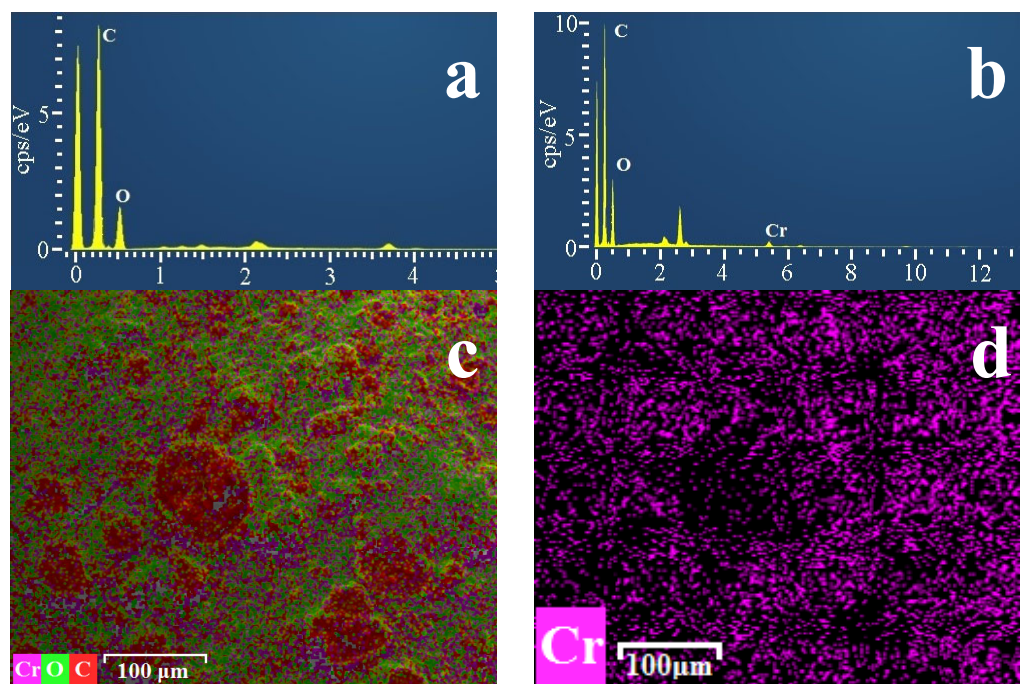

Şekil 4. K-VÇKÇ için; (a) adsorpsiyon öncesi EDX spektrumu, (b) adsorpsiyon sonrası EDX spektrumu, (c) adsorpsiyon sonrasında elementlerin yüzey üzerindeki dağılım haritası, (d) adsorpsiyon sonrasında Cr iyonlarının yüzey üzerindeki dağılım haritası

EDX analizi ile; her iki adsorbanın yapılarındaki karbon ve oksijenin varlı̆̆ teyit edilmiștir. Elde edilen sonuçlar elementel analiz sonuçları ile de uyumludur.

Adsorpsiyon sonrasindaki numunelerin analizinde; yapıda krom bulunmuş olması, kromun adsorbanlara tutunmuş olduğunu göstermektedir. Ayrıca element haritası verilerinden, kromun adsorban yüzeyine homojen bir şekilde dağıldığı da görülebilmektedir.

\subsection{Adsorpsiyon Çalışmaları}

\subsubsection{Adsorban Miktarının Etkisi}

Adsorpsiyon için optimum adsorban miktarını belirlemek amacıyla farklı miktarlardaki adsorbanların üzerine $55 \mathrm{mg} / \mathrm{L}$ 'lik ve pH'1 2'ye ayarlanmış $\mathrm{Cr}(\mathrm{VI})$ çözeltisinden eklendi ve 2'şer saat karıştırıldı. Şekil 5 ve 6'da adsorban miktarlarına karşılık adsorpsiyon yüzdesi ve birim adsorban kütlesi başına tutulan madde miktarı $\left(\mathrm{q}_{\mathrm{e}}\right)$ değişimleri grafiğe geçirilerek verilmiştir.

Şekil 5 ve 6 incelendiğinde adsorban miktarının arttıkça adsorpsiyon yüzdesinin arttı̆̆ görülmektedir. Belli bir değere ulaştıktan sonra adsorban miktarının artırılması adsorpsiyon yüzdesini fazla etkilememektedir. Adsorpsiyon yüzdesindeki artış, adsorban miktarının artırılması ile adsorban yüzeyindeki aktif bölge sayısının artması ile açıklanabilir [27].

Adsorban miktarının artması ile birim adsorban kütlesi başına tutulan madde miktarının $\left(\mathrm{q}_{\mathrm{e}}\right)$ azalmasının sebebi ise; çözelti konsantrasyonu sabit olduğu halde adsorban miktarının artışından dolayı, her bir adsorban taneciği başına düşen adsorbat miktarının azalmasıdır.

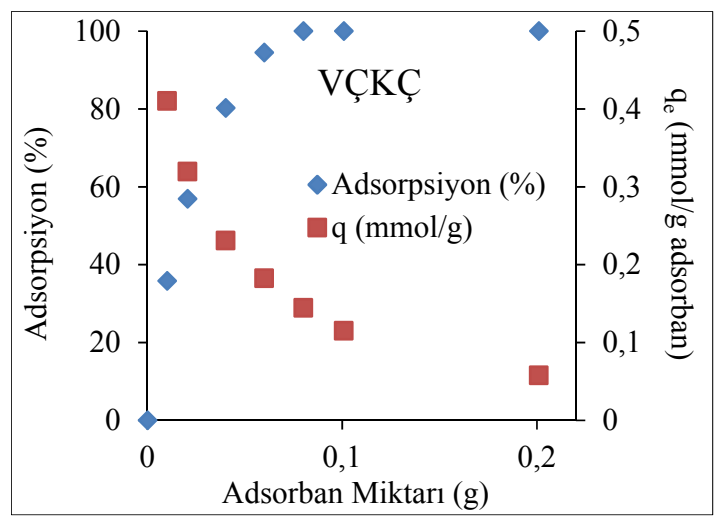

Şekil 5. VÇKÇ için $\mathrm{Cr}(\mathrm{VI})$ adsorpsiyonuna adsorban miktarlarının etkisi 


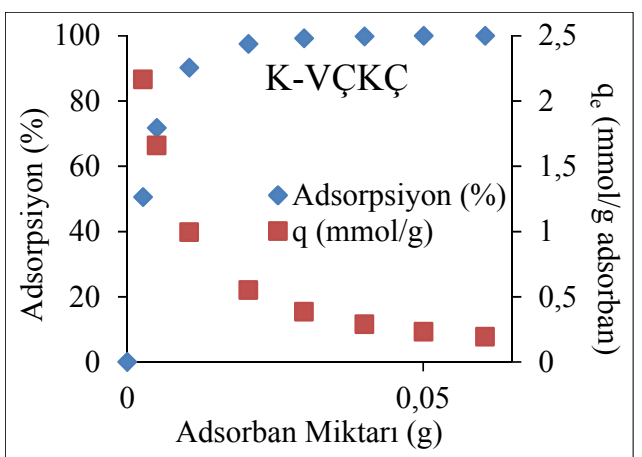

Şekil 6. K-VÇKÇ için Cr(VI) adsorpsiyonuna adsorban miktarlarının etkisi

Deney sonuçlarına göre optimum adsorban miktarları VÇKÇ için $5 \mathrm{~g} / \mathrm{L}$ ve $\mathrm{K}-\mathrm{VCCKÇ}$ için $1,5 \mathrm{~g} / \mathrm{L}$ olarak belirlenmiştir.

\subsubsection{Adsorpsiyon İzotermleri}

Farklı konsantrasyonlardaki, pH'ları 2'ye ayarlanmış $\quad \mathrm{Cr}(\mathrm{VI}) \quad$ çözeltileri, optimum miktarlardaki adsorbanlar ile karıştırılarak adsorpsiyon denemeleri yapılmıştır. Bu denemeler sonucunda elde edilen veriler ile hazırlanan adsorpsiyon izotermleri ve $\mathrm{Cr}(\mathrm{VI})$ adsorpsiyon yüzdesi değişimleri Şekil 7 ve 8 'de verilmiştir.

Şekil 7 ve 8 'de $\mathrm{Cr}(\mathrm{VI})$ başlangıç derişiminin arttırılmasıyla birim adsorban kütlesi başına tutulan madde miktarının $\left(\mathrm{q}_{\mathrm{e}}\right)$ arttı̆ $\mathrm{g}, \quad \mathrm{Cr}(\mathrm{VI})$ adsorpsiyon yüzdesinin ise azaldığı görülmektedir. Konsantrasyon artış1 ile adsorpsiyon yüzdesinin azalmasının sebebi; adsorban miktarı sabit olduğu için, adsorban üzerinde bulunan her bir aktif bölge başına düşen adsorbat miktarının artmasıdır. $\mathrm{Bu}$ sebeple konsantrasyon artışı ile adsorban tarafindan tutulmayan adsorbat miktarı da artış göstermektedir. Birim adsorban kütlesi başına tutulan madde miktarının $\left(\mathrm{q}_{\mathrm{e}}\right)$ artmasının sebebi ise; adsorbandaki her bir aktif bölge başına düşen adsorbat miktarı arttı̆̆ı için, bu bölgelerdeki tutunma miktarlarının da artmasidır. $\mathrm{Bu}$ da adsorbanın maksimum kapasitesine yaklaşmasını sağlar ve birim adsorban kütlesi başına tutulan madde miktarı da bu yüzden artış gösterir. $\mathrm{Bu}$ sonuçtan hareketle, sistem tasarımı yapıllırken en uygun giderim verimi ile adsorban performans1 arasında optimum bir seçim yapılması gereklidir.

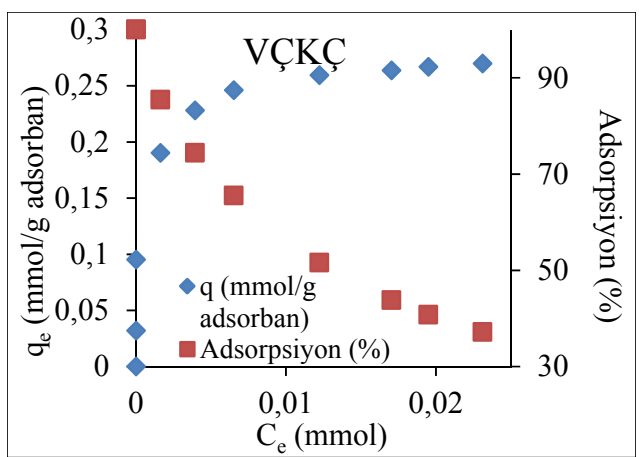

Şekil 7. VÇKÇ için adsorpsiyon izotermi ve $\mathrm{Cr}(\mathrm{VI})$ adsorpsiyon yüzdesinin değişimi

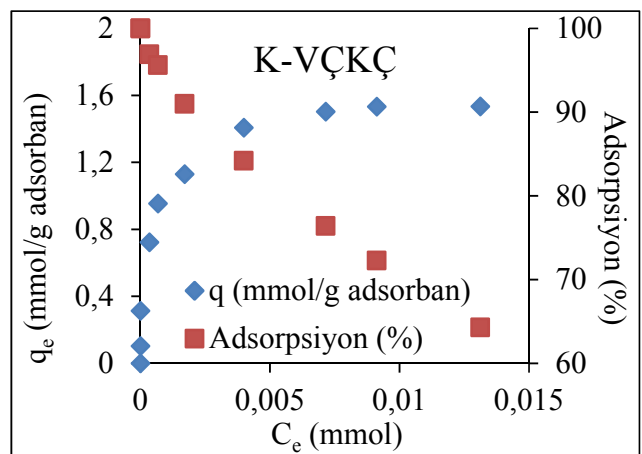

Şekil 8. K-VÇKÇ için adsorpsiyon izotermi ve $\mathrm{Cr}(\mathrm{VI})$ adsorpsiyon yüzdesinin değişimi

Elde edilen verilerin Langmuir, Freundlich, Scatchard, Dubinin-Radushkevich ve Temkin izotermlerine uygulanması sonucunda elde edilen izoterm parametreleri Çizelge 1'de verilmiştir.

İzoterm parametrelerine göre adsorpsiyonun, en yüksek $\mathrm{R}^{2}$ değerinin elde edildiği Langmuir izotermine uygun olduğu, genellikle adsorpsiyon mekanizmasının tek tabakalı ve adsorban yüzeyinin homojen olduğu söylenebilir [28]. Freundlich izotermi için $\mathrm{R}^{2}$ değerlerinin 0,94 'ten daha büyük değerlerde bulunması, denemelerde fiziksel adsorpsiyonun da meydana geldiğine işaret etmektedir. Scatchard izotermi için elde edilen 0,95 'in üzerindeki $\mathrm{R}^{2}$ değerleri adsorpsiyonun Langmuir izotermine uygunluğunu desteklemektedir. Dubinin-Radushkevich (D-R) izoterminden hesaplanan adsorpsiyon enerjisi (E) değerlerinin 8-16 $\mathrm{kJ} / \mathrm{mol}$ aralığında olması adsorpsiyonda kimyasal adsorpsiyon 
mekanizmasının daha baskın olduğuna işaret etmektedir. D-R izotermi için $\mathrm{R}^{2}$ değerlerinin 0,97'nin üzerinde bulunmuş olması, adsorpsiyonlarda etkili olan mekanizmaların bu modelle belirlenebileceğine işaret etmektedir. Temkin izoterm modeli için $\mathrm{R}^{2}$ değerlerinin 0,95 'ten daha büyük olarak elde edilmiş olması adsorban katmanlarında bulunan tüm moleküllerin adsorpsiyon ısısının lineer olarak azaldığına işaret etmektedir.

Çizelge 1. İzoterm, kinetik ve termodinamik parametreler

\begin{tabular}{|c|c|c|c|}
\hline \multicolumn{2}{|c|}{ Parametreler } & VÇKÇ & K-VÇKÇ \\
\hline \multirow{3}{*}{ Freundlich } & $\mathbf{K}_{\mathrm{F}}$ & 0,443 & 4,062 \\
\hline & $n$ & 7,981 & 4,869 \\
\hline & $\mathbf{R}^{2}$ & 0,942 & 0,9519 \\
\hline \multirow{3}{*}{ Langmuir } & $\mathbf{K}_{\mathbf{b}}$ & 1199 & 2080,7 \\
\hline & \begin{tabular}{|l|}
$A_{s}(\mathrm{mmol} / \mathrm{g})$ \\
\end{tabular} & 0,278 & 1,602 \\
\hline & $\mathbf{R}^{2}$ & 0,9999 & 0,9995 \\
\hline \multirow{3}{*}{ Scatchard } & $\mathbf{K}_{\mathrm{s}}$ & 1315,7 & 2290,5 \\
\hline & $\mathrm{Q}_{\mathrm{s}}(\mathrm{mmol} / \mathrm{g})$ & 0,276 & 1,569 \\
\hline & $\mathbf{R}^{2}$ & 0,9932 & 0,9553 \\
\hline \multirow{4}{*}{$\begin{array}{l}\text { Dubinin- } \\
\text { Radushkevich }\end{array}$} & $\mathbf{X}_{\mathbf{m}}$ & 0,329 & 0,8077 \\
\hline & $\mathbf{K}$ & 0,0021 & 0,0028 \\
\hline & $E(\mathrm{~kJ} / \mathrm{mol})$ & 15,430 & 13,363 \\
\hline & $\mathbf{R}^{2}$ & 0,9712 & 0,9766 \\
\hline \multirow{3}{*}{ Temkin } & b (J/mol) & 1649,6 & 206,0 \\
\hline & $A_{T}(L / g)$ & 110,4 & 15,6 \\
\hline & $\mathbf{R}^{2}$ & 0,9610 & 0,9578 \\
\hline \multirow{3}{*}{$\begin{array}{l}\text { Yalancı } 1 . \\
\text { mertebeden } \\
\text { kinetik model }\end{array}$} & $\mathbf{R}^{2}$ & 0,9797 & 0,987 \\
\hline & Kad & 0,050 & 0,039 \\
\hline & $q(\mathrm{mmol} / \mathrm{g})$ & 0,145 & 0,562 \\
\hline \multirow{4}{*}{$\begin{array}{l}\text { Yalancı } 2 . \\
\text { mertebeden } \\
\text { kinetik model }\end{array}$} & $\mathbf{R}^{2}$ & 0,9993 & 0,9996 \\
\hline & $\mathbf{h}$ & 0,0282 & 0,0789 \\
\hline & $\mathbf{k}_{\mathbf{2}}$ & 0,0707 & 0,1112 \\
\hline & $\mathrm{q}(\mathrm{mmol} / \mathrm{g})$ & 0,200 & 0,842 \\
\hline \multicolumn{2}{|c|}{$\Delta \mathbf{H}^{\circ}(\mathrm{J} / \mathrm{mol})$} & $6.801,6$ & $61.762,2$ \\
\hline \multicolumn{2}{|c|}{$\Delta \mathbf{S}^{\circ}(\mathrm{J} / \mathrm{K} \cdot \mathrm{mol})$} & 35,0 & 252,0 \\
\hline \multirow{4}{*}{$\Delta \mathbf{G}^{\circ}(\mathbf{J} / \mathrm{mol})$} & $T=298,15 \mathrm{~K}$ & $-3.638,46$ & $-13.368,3$ \\
\hline & $T=308,15 \mathrm{~K}$ & $-3.988,6$ & $-15.888,2$ \\
\hline & $T=318,15 \mathrm{~K}$ & $-4.338,8$ & $-18.408,1$ \\
\hline & $T=328,15 \mathrm{~K}$ & $-4.689,0$ & $-20.928,0$ \\
\hline
\end{tabular}

Langmuir izotermine göre hesaplanan adsorpsiyon kapasiteleri VÇKÇ için 14,455 mg/g $(0,278 \mathrm{mmol} / \mathrm{g})$, K-VÇKÇ için 86,298 $\mathrm{mg} / \mathrm{g}$ $(1,602 \mathrm{mmol} / \mathrm{g})$ olarak hesaplanmıştır. Ayrıca Langmuir modelinin uygunluğunu destekleyen Scatchard modelinden hesaplanan maksimum adsorpsiyon kapasiteleri $\left(\mathrm{Q}_{\mathrm{s}}\right)$ de bu değerlere yakın olarak bulunmuştur. Çizelge 2'de, literatürde Cr(VI) adsorpsiyonu için kullanımı önerilen bazı adsorbanların maksimum adsorpsiyon kapasiteleri verilmiştir. D-R modeli ile adsorpsiyon enerjileri VÇKÇ için 15,430 ve K-VÇKÇ için 13,363 kJ/mol olarak bulunmuştur. $\mathrm{Bu}$ değerlerin $8-16 \mathrm{~kJ} / \mathrm{mol}$ aralığında olması adsorpsiyon mekanizmasında kompleks oluşumu ve iyon değişimininin daha etkili olduğuna işaret eder [29,30].

Çizelge 2. Literatürdeki bazı adsorbanların $\mathrm{Cr}(\mathrm{VI})$ adsorpsiyon kapasiteleri

\begin{tabular}{|c|c|c|}
\hline Adsorban & $\begin{array}{c}\text { Adsorpsiyon } \\
\text { kapasitesi }\end{array}$ & Kaynak \\
\hline VÇKÇ & $14,46 \mathrm{mg} / \mathrm{g}$ & \multirow{2}{*}{$\begin{array}{c}\mathrm{Bu} \\
\text { çalışma }\end{array}$} \\
\hline K-VÇKÇ & $86,30 \mathrm{mg} / \mathrm{g}$ & \\
\hline Vişne çekirdeği kabuğu & $13,57 \mathrm{mg} / \mathrm{g}$ & \multirow[b]{2}{*}{ [11] } \\
\hline $\begin{array}{l}\text { Kitosan kaplı vişne } \\
\text { çekirdeği kabuğu }\end{array}$ & $24,50 \mathrm{mg} / \mathrm{g}$ & \\
\hline Kitosan & $35,60 \mathrm{mg} / \mathrm{g}$ & [31] \\
\hline $\begin{array}{l}\text { Kitosan kaplı kuşburnu } \\
\text { çekirdeği kabuğu }\end{array}$ & $34,13 \mathrm{mg} / \mathrm{g}$ & {$[32]$} \\
\hline $\begin{array}{l}\text { Manyetik siklodekstrin- } \\
\text { kitosan/grafen oksit }\end{array}$ & $67,66 \mathrm{mg} / \mathrm{g}$ & [33] \\
\hline $\begin{array}{l}\text { Hindistan cevizi ağacı } \\
\text { kabuğu aktif karbonu }\end{array}$ & $3,46 \mathrm{mg} / \mathrm{g}$ & [34] \\
\hline $\begin{array}{l}\text { Yağ palmiyesi kabuğu } \\
\text { aktif karbonu }\end{array}$ & $44,68 \mathrm{mg} / \mathrm{g}$ & \multirow{3}{*}{ [4] } \\
\hline $\begin{array}{l}\text { Kitosan kaplı yağ } \\
\text { palmiyesi kabuğu aktif } \\
\text { karbonu }\end{array}$ & $52,68 \mathrm{mg} / \mathrm{g}$ & \\
\hline $\begin{array}{l}\text { Sülfürik asit ile muamele } \\
\text { edilmiş kitosan kaplı yağ } \\
\text { palmiyesi kabuğu aktif } \\
\text { karbonu }\end{array}$ & $60,25 \mathrm{mg} / \mathrm{g}$ & \\
\hline $\mathrm{Fe}_{3} \mathrm{O}_{4}$-Kitosan kompoziti & $90,9 \mathrm{mg} / \mathrm{g}$ & [5] \\
\hline $\begin{array}{l}\text { Çapraz bağlı manyetik } \\
\text { kitosan boncukları }\end{array}$ & $69,4 \mathrm{mg} / \mathrm{g}$ & {$[18]$} \\
\hline $\begin{array}{l}\text { Hindistan cevizi kabuğu } \\
\text { ticari aktif karbonu }\end{array}$ & $4,72 \mathrm{mg} / \mathrm{g}$ & \multirow{5}{*}{ [35] } \\
\hline $\begin{array}{l}\text { Nitrik asit ile oksitlenmiş } \\
\text { Hindistan cevizi kabuğu } \\
\text { ticari aktif karbonu }\end{array}$ & $10,44 \mathrm{mg} / \mathrm{g}$ & \\
\hline $\begin{array}{l}\text { Hindistan cevizi kabuğu } \\
\text { çarı }\end{array}$ & $2,18 \mathrm{mg} / \mathrm{g}$ & \\
\hline $\begin{array}{l}\text { Kitosan kaplı sülfürik asit } \\
\text { ile oksitlenmiş Hindistan } \\
\text { cevizi kabuğu çarı }\end{array}$ & $8,95 \mathrm{mg} / \mathrm{g}$ & \\
\hline $\begin{array}{l}\text { Nitrik asit ile oksitlenmiş̧ } \\
\text { Hindistan cevizi kabuğu } \\
\text { çarı }\end{array}$ & $10,88 \mathrm{mg} / \mathrm{g}$ & \\
\hline
\end{tabular}


Çizelge 2'de bazı ham malzemeler ve kitosan kaplanmış adsorbanların $\mathrm{Cr}(\mathrm{VI})$ tutma kapasiteleri görülmektedir. Buradan, ham malzemelerin kapasitelerinin kitosan kaplı adsorbanlardan daha düşük olduğu görülmüştür. Bizim çalışmamızda kullandığımız kompozit adsorbanımız (K-VÇKÇ) için hesaplanan kapasitenin ise; Çizelge 2'de verilen kompozit adsorbanların birçoğunun kapasitesinden daha yüksek olduğu bulunmuştur.

\subsubsection{Temas Süresinin Adsorpsiyona Etkisi ve Adsorpsiyon Kinetiği}

$55 \mathrm{mg} / \mathrm{L}$ 'lik pH'sı 2'ye ayarlanmış $\mathrm{Cr}(\mathrm{VI})$ çözeltisi, belirlenmiş olan optimum adsorban miktarlarında tartılan adsorbanların üzerine ilave edilerek farklı temas süreleri için adsorpsiyon denemeleri yapılmıştır. Temas süresinin değişimine göre $\mathrm{Cr}(\mathrm{VI})$ adsorpsiyon yüzdelerinin değişimleri Şekil 9'da verilmiştir.

Deneyler sonucunda adsorban yüzeyinin tamamen yüklenmiş olmasından dolayı 120. dakikadan itibaren adsorpsiyonun dengeye ulaştı $\breve{g}_{1}$ görülmüştür.

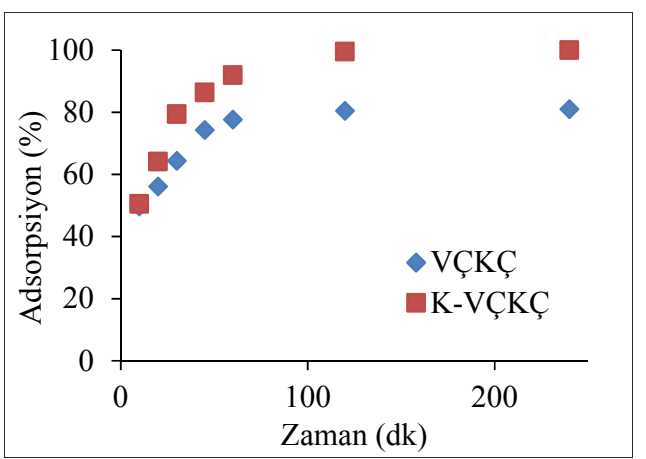

Şekil 9. Temas süresi ile $\mathrm{Cr}(\mathrm{VI})$ adsorpsiyon yüzdesinin değişimi

Temas süresi çalışması ile elde edilen verilerin yalancı birinci mertebeden ve yalancı ikinci mertebeden kinetik modellere uygulanması ile hesaplanan kinetik model sabitleri ile adsorpsiyon kapasiteleri ve modellerin korelasyon katsayıları Çizelge 1'de verilmiştir. Burada hesaplanan adsorpsiyon kapasitesi (q) değerleri görülmektedir. 2 saatlik temas süresi sonunda deneysel olarak bulunan adsorpsiyon kapasiteleri $\left(\mathrm{q}_{\mathrm{e}}\right)$ ise $\mathrm{VÇKÇ}$ için $0,192 \mathrm{mmol} / \mathrm{g}$ ve K-VÇKÇ için $0,785 \mathrm{mmol} / \mathrm{g}$ olmuştur.

Kinetik modellerin, korelasyon katsayılarının büyüklüğü ve hesaplanan adsorpsiyon kapasitelerinin deneysel adsorpsiyon kapasitelerine olan yakınlığı karşılaştırıldığında sistemin yalancı ikinci mertebeden kinetik modele daha uygun olduğu görülmüştür. $\mathrm{Bu}$ da adsorpsiyon mekanizmasında kimyasal adsorpsiyonun daha etkili olduğuna işaret etmektedir [36].

\subsection{4. Çözelti pH'sının Adsorpsiyona Etkisi}

Farklı pH'larda ayarlanmış 55 mg/L'lik Cr(VI) çözeltileri, optimum miktarlardaki adsorbanların üzerine eklenerek 120 dakika temas süresi boyunca adsorpsiyon denemeleri gerçekleştirildi. Elde edilen sonuçlarla pH'nın adsorpsiyona etkisi grafiği Şekil 10’da verilmiştir.

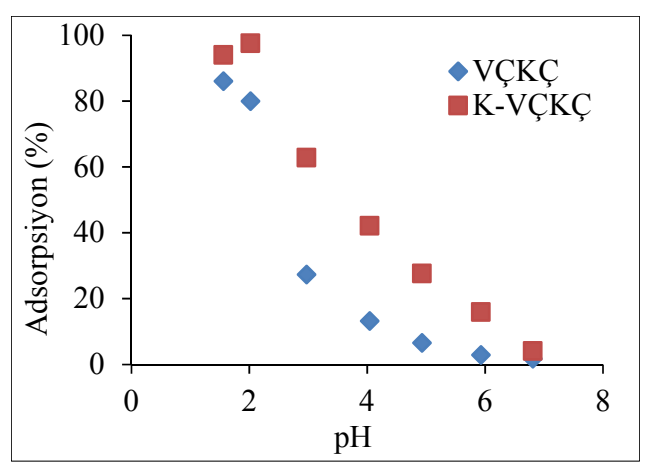

Şekil 10. $\mathrm{pH}$ değişimine karşılık $\mathrm{Cr}(\mathrm{VI})$ adsorpsiyon yüzdesinin değişimi

Deneyler sonucunda VÇKÇ için 1,56, K-VÇKÇ için ise $2 \mathrm{pH}$ değerlerinde adsorpsiyon yüzdesinin en yüksek olduğu görülmüştür. Devamında da $\mathrm{pH}$ arttıkça adsorpsiyon yüzdesi düşmüştür.

Adsorpsiyonun düşük pH'larda verimli olmasının sebebi adsorban yüzeyinde bulunan karboksil, amin vb. fonksiyonel grupların düşük pH'larda protonlanmasıdır. $\mathrm{Cr}(\mathrm{VI})$ iyonları çözelti içerisinde $\mathrm{HCrO}_{4}^{-}, \mathrm{CrO}_{4}^{2-}$ ve $\mathrm{Cr}_{2} \mathrm{O}_{7}^{2-}$ formlarında anyon olarak bulunduğu için protonlanarak pozitif yüklenmiş olan adsorban yüzeyi tarafından çekilir 
Kitosan-Vişne Çekirdeği Kabuğu Pirolitik Çarı Kompozit Boncuklarının Sentezi ve Karakterizasyonu: Cr(VI) Gideriminde Kullanılması

[37]. Ayrıca düşük pH'larda Cr(VI)'nın Cr(III)'e indirgenmesi de oldukça düşük düzeydedir. Ancak yüksek pH'larda çözeltideki Cr(VI) iyonları katyonik halde bulunan Cr(III)'e indirgenir [38].

\subsubsection{Sıcaklığın Adsorpsiyona Etkisi ve Termodinamik Hesaplamalar}

Cr(VI) adsorpsiyonunun sıcaklıkla değişimini incelemek amaciyla pH'sı 2'ye ayarlanmış $55 \mathrm{mg} / \mathrm{L}$ 'lik Cr(VI) çözeltisi, optimum miktarda tartılan adsorbanların üzerine ilave edilerek 120 dakika'lık temas süresi boyunca farklı sicaklıklarda adsorpsiyon denemeleri yapıldı. Elde edilen sonuçlardan hazırlanan, sıcaklığa karşılık termodinamik denge sabitinin logaritmasının ve $\mathrm{Cr}(\mathrm{VI})$ adsorpsiyon yüzdelerinin değişimini gösteren grafikler Şekil 11 ve 12'de verilmiştir.

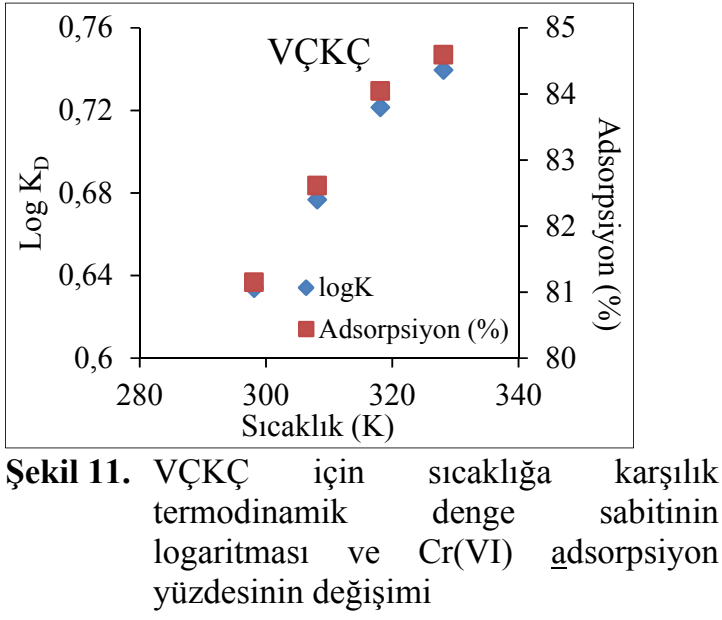

Şekil 11 ve 12'de görülmektedir ki, sicaklığın artırılması Cr(VI) adsorpsiyonunu az da olsa artırmıştır. Adsorpsiyon yüzdesinin artışının az olması sebebiyle ve adsorpsiyonu yüksek sıcaklıklarda işletmenin beraberinde getireceği ek maliyetler de göz önünde bulundurularak $25{ }^{\circ} \mathrm{C}$ optimum sicaklık seçilmiştir. Adsorpsiyon yüzdesinin sıcaklıkla artış göstermesi, reaksiyonun endotermik olduğunu göstermektedir. Adsorpsiyonun sıcaklıkla artması adsorban ile adsorbat arasında kimyasal etkileşimler meydana geldiğine işaret edebilir [39].

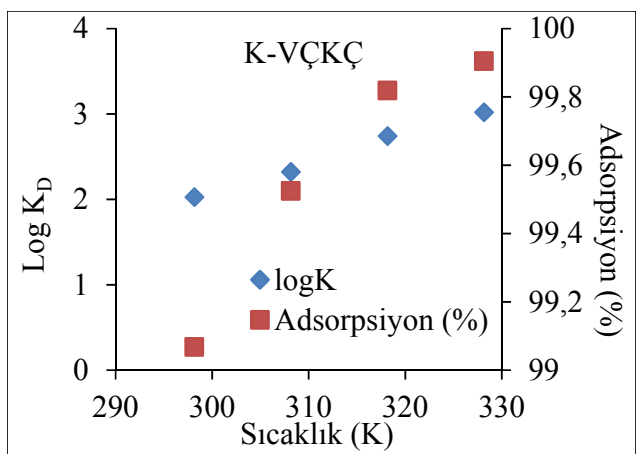

Şekil 12. K-VÇKÇ için sıcaklığa karşılık termodinamik denge sabitinin logaritması ve $\mathrm{Cr}(\mathrm{VI})$ adsorpsiyon yüzdesinin değişimi

Sicaklığın adsorpsiyona etkisinin belirlenmesi deneylerinden elde edilen veriler kullanılarak 1/T'ye karşılık $\log K_{D}$ grafiği çizilmiş ve bu grafik yardımıyla Eşitlik 13 ve 14 kullanılarak termodinamik parametreler hesaplanmıştır. $\mathrm{Bu}$ parametreler Çizelge 1'de gösterilmiştir.

Termodinamik parametrelerden entalpi değişiminin $\left(\Delta \mathrm{H}^{\circ}\right)$ pozitif olması adsorpsiyon reaksiyonunun endotermik olduğu sonucunu doğrulamaktadır [40]. Entropi değişimininin $\left(\Delta S^{\circ}\right)$ pozitif olması adsorpsiyon süreci boyunca adsorban ve çözelti arayüzeyinde düzensizliğin artış gösterdiğine işaret eder [41]. Son olarak Gibbs serbest enerjisinin $\left(\Delta \mathrm{G}^{\circ}\right)$ negatif olması sürecin belirtilen sicaklıklarda istemli olduğunu ifade etmektedir [42]. Ayrıca belirlenen entalpi ve entropi değişimleri Eşitlik 14'te yerine konulduğunda, VÇKÇ adsorbanı için $-78,9{ }^{\circ} \mathrm{C}$ ve K-VÇKÇ adsorbanı için $-28{ }^{\circ} \mathrm{C}$ 'nin üzerindeki sıcaklıklarda sürecin istemli olduğu görülmektedir.

\section{SONUÇLAR}

$\mathrm{Bu}$ çalışmada vişne çekirdeği kabuğundan üretilmiş olan pirolitik çarın (VÇKÇ) ve bu pirolitik çarın kitosanla kompozitinin oluşturulması ile elde edilen boncuk adsorbanın (K-VÇKÇ) Cr(VI) giderimindeki performansı incelenmiştir. 
Optimum adsorban miktarları VÇKÇ için $5 \mathrm{~g} / \mathrm{L}$ ve $\mathrm{K}-\mathrm{VÇKÇ} \mathrm{için} \mathrm{1,5} \mathrm{g/L} \mathrm{olarak} \mathrm{bulunmuştur.}$ Adsorpsiyonun tüm izoterm modelleri ile uyum içerisinde olmasına karşın en uygun modelin Langmuir izotermi olduğu bulunmuş ve bu izotermden, maksimum adsorpsiyon kapasiteleri VÇKÇ için 14,455 $\mathrm{mg} / \mathrm{g} \quad(0,278 \mathrm{mmol} / \mathrm{g})$, K-VÇKÇ için $86,298 \mathrm{mg} / \mathrm{g}(1,602 \mathrm{mmol} / \mathrm{g})$ olarak hesaplanmıştır. $\mathrm{Cr}(\mathrm{VI})$ gideriminin asidik pH'larda yüksek olduğu ve pH artışı ile giderimin azaldığı görülmüştür. En yüksek giderimin elde edildiği $\mathrm{pH}$ değerleri VÇKÇ için 1,56 ve K-VÇKÇ için 2'dir. Adsorpsiyon 120 dakika'lık temas süresi sonunda dengeye ulaşmıştır. Ayrıca çalışmada adsorpsiyon kinetiğinin yalancı ikinci dereceden kinetik modele daha uygun olduğu ifade edilmiştir. $\mathrm{Cr}(\mathrm{VI})$ gideriminin sıcaklık artışı ile doğru orantılı olduğu görülmüş bu sebeple reaksiyonun endotermik olduğu ifade edilmiştir. Ayrıca termodinamik hesaplamalar da bu sonucu doğrulamasının yanında Gibbs serbest enerjisinin negatif değerlerde bulunmasından dolayı adsorpsiyonun istemli olduğu da belirtilmiştir.

İzoterm çalışmaları, kinetik ve termodinamik hesaplamalar ile adsorpsiyonda kimyasal adsorpsiyon mekanizmasının daha baskın olduğu sonucuna varılmıştır.

Adsorbanların karakterizasyonları için yapılan FTIR, SEM ve EDX analizleri de Cr(VI)'nın adsorbanların yüzeylerine yüklendiğini göstermiştir. BET yüzey alanı analizi sonucunda VÇKÇ adsorbanının yüzey alanının $224,148 \mathrm{~m}^{2} / \mathrm{g}$, K-VÇKÇ adsorbanının yüzey alanının $7,353 \mathrm{~m}^{2} / \mathrm{g}$ olduğu belirlenmiştir.

$\mathrm{Bu}$ çalışma sonucunda ekonomik bir değeri olmayan vişne çekirdeğinin pirolitik çar haline getirilerek ve bu pirolitik çarın kitosanla kompozitinin oluşturularak atık sulardan $\mathrm{Cr}(\mathrm{VI})$ gideriminde adsorban olarak verimli bir şekilde kullanılabileceği ortaya konmuştur.

\section{KAYNAKLAR}

1. Srivastava, S., Agrawal, S.B., Mondal, M.K., 2015. A Review on Progress of Heavy Metal Removal Using Adsorbents of Microbial and
Plant Origin, Environ Sci Pollut R, 22(20), 15386-15415.

2. Dündar, M.Ş., Altundağ, H., Kaygaldurak, S., Şar, V., Acar, A., 2015. Çeşitli Endüstriyel Atık Sularda Ağır Metal Düzeylerinin Belirlenmesi, Sakarya University Journal of Science, 16(1), 6-12.

3. Canlı, M., Abalı, Y., Öztekin, B., Şirin, K., 2014. Deri Sanayi Atık Sularından Krom (VI) İyonunun Adsorbsiyonu-Removal of Chromium (VI) Ion From Leather Wastewaters By Adsorption, Celal Bayar Üniversitesi Fen Bilimleri Dergisi, 10(1), 11-24.

4. Nomanbhay, S.M., Palanisamy, K., 2005. Removal of Heavy Metal from Industrial Wastewater Using Chitosan Coated Oil Palm Shell Charcoal, Electron. J. Biotechn., 8(1), 43-53.

5. Ravi, T., Jabasingh, S.A., 2018. Preparation and Characterization of Higher Degreedeacetylated Chitosan-coated Magnetic Adsorbent for the Removal of Chromium (VI) from its Aqueous Mixture, J. Appl. Polym. Sci., 135(9).

6. Dinari, M., Haghighi, A., 2018. UltrasoundAssisted Synthesis of Nanocomposites Based on Aromatic Polyamide and Modified $\mathrm{ZnO}$ Nanoparticle for Removal of Toxic Cr(VI) from Water, Ultrason Sonochem, 41, 75-84.

7. Sezer, K., 2010. Şeker Pancarı Küspesinden Elde Edilen Aktif Karbonun Atıksulardaki 2,4D ve Metribuzin Pestisitlerinin Adsorpsiyonunda Kullanılabilirliğinin Araştırılması. Hacettepe Üniversitesi, Fen Bilimleri Enstitüsü, Yüksek Lisans Tezi, Ankara.

8. Lim, A.P., Aris, A.Z., 2014. A Review on Economically Adsorbents on Heavy Metals Removal in Water and Wastewater, Rev. Environ. Sci. Bio., 13(2), 163-181.

9. TÜIK: 'Kaynak: https://biruni.tuik.gov.tr/ medas $/$ $: \mathrm{kn}=92 \&$ locale $=$ tr, $\quad($ Erişim Tarihi: 11.07.2018)

10. Yılmaz, C., Gökmen, V., 2013. Compositional Characteristics of Sour Cherry Kernel and its Oil as Influenced by Different Extraction and Roasting Conditions, Ind. Crop. Prod., 49, 130-135. 
11. Altun, T., 2019. Chitosan-coated Sour Cherry Kernel Shell Beads: an Adsorbent for Removal of Cr (VI) from Acidic Solutions, Journal of Analytical Science and Technology, 10(1), 14.

12. Alvarez, J., Lopez, G., Amutio, M., Bilbao, J., Olazar, M., 2016, Preparation of Adsorbents from Sewage Sludge Pyrolytic Char by Carbon Dioxide Activation, Process Safety and Environmental Protection, 103, 76-86.

13. Kar, H., 2010. Styrax officinalis L. Maki Bitkisi Tohumlarından Aktif Karbon Üretimi ve $\mathrm{Cr}$ (VI) İyonu Sorpsiyonunun İncelenmesi. Selçuk Üniversitesi, Fen Bilimleri Enstitüsü, Yüksek Lisans Tezi, Konya.

14. Kutlu, P., 2015. Modifiye Kitosan Kompozitleri Üzerinde Lakkaz İmmobilizasyonu, Karakterizasyonu ve İmmobilize Enzim ile Tekstil Boyalarının Giderim Kinetiğinin İncelenmesi. Celal Bayar Üniversitesi Fen Bilimleri Enstitüsü, Yüksek Lisans Tezi, Manisa.

15. Yang, S., Luo, S., Liu, C., Wei, W., 2012. Direct Synthesis of Graphene-chitosan Composite and its Application as an Enzymeless Methyl Parathion Sensor, Colloids and Surfaces B: Biointerfaces, 96, 75-79.

16. Şahin, M., 2007. Kitosanın Schiff Baz Türevlerinin Sentezi ve Metal Komplekslerinin İncelenmesi. Selçuk Üniversitesi Fen Bilimleri Enstitüsü, Doktora Tezi, Konya.

17. Sargın, I., Kaya, M., Arslan, G., Baran, T., Ceter, T., 2015. Preparation and Characterisation of Biodegradable Pollenchitosan Microcapsules and its Application in Heavy Metal Removal, Bioresource Technol, 177, 1-7.

18. Huang, G.L., Zhang, H.Y., Shi, J.X., Langrish, T.A.G., 2009. Adsorption of Chromium(VI) from Aqueous Solutions Using Cross-Linked Magnetic Chitosan Beads, Ind Eng Chem Res, 48(5), 2646-2651.

19. Pap, S., Radonic, J., Trifunovic, S., Adamovic, D., Mihajlovic, I., Miloradov, M.V., Sekulic, M.T., 2016. Evaluation of the Adsorption Potential of Eco-friendly Activated Carbon Prepared from Cherry Kernels for the Removal of $\mathrm{Pb}^{2+}, \mathrm{Cd}^{2+}$ and $\mathrm{Ni}^{2+}$ from Aqueous Wastes, $\mathrm{J}$ Environ Manage, 184, 297-306.
20. Vanamudan, A., Pamidimukkala, P., 2015. Chitosan, Nanoclay and Chitosan-nanoclay Composite as Adsorbents for Rhodamine-6G and the Resulting Optical Properties, Int. J. Biol. Macromol, 74, 127-135.

21. Kolodynska, D., Bak, J., Koziol, M., Pylypchuk, L.V., 2017. Investigations of Heavy Metal Ion Sorption Using Nanocomposites of Iron-Modified Biochar, Nanoscale Res. Lett. 12.

22. Guo, J., Lua, A.C., 2000. Effect of Heating Temperature on the Properties of Chars and Activated Carbons Prepared From Oil Palm Stones, Journal of Thermal Analysis and Calorimetry, 60(2), 417-425.

23. Altun, T., Parlayıcı, S., 2017. Sepiolit-Kitosan Kompositlerinin Sentezi ve Bu Kompozit ile Sulu Çözeltilerden Cr(VI) Adsorpsiyonunun İncelenmesi, Selçuk Üniversitesi Mühendislik, Bilim ve Teknoloji Dergisi, 6(2), 242-254.

24. Chen, Y.W., Wang, J.L., 2012. Removal of Radionuclide $\mathrm{Sr}^{2+}$ Ions from Aqueous Solution Using Synthesized Magnetic Chitosan Beads, Nucl. Eng. Des., 242, 445-451.

25. Parlayı1c1, S., Altun, T., 2017. Kitosan Kaplı Kaolin Boncukların Sulu Çözeltilerden Krom(VI) Uzaklaştırılmasında Adsorban Olarak Kullanımı, Selçuk Üniversitesi Mühendislik, Bilim ve Teknoloji Dergisi, 6(1), 140-151.

26. Sharma, G., Naushad, M., Al-Muhtaseb, A.H., Kumar, A., Khan, M.R., Kalia, S., Shweta, Bala, M., Sharma, A., 2017. Fabrication and Characterization of Chitosan-crosslinked-poly (alginic acid) Nanohydrogel for Adsorptive Removal of $\mathrm{Cr}(\mathrm{VI})$ Metal Ion from Aqueous Medium, Int J Biol Macromol, 95, 484-493.

27. Moussavi, G., Mahmoudi, M., 2009. Removal of Azo and Anthraquinone Reactive Dyes from Industrial Wastewaters Using $\mathrm{MgO}$ Nanoparticles, J Hazard Mater, 168(2-3), 806-812.

28. Nameni, M., Moghadam, M.R.A., Arami, M., 2008. Adsorption of Hexavalent Chromium from Aqueous Solutions by Wheat Bran, Int J Environ Sci Te, 5(2), 161-168.

29. Altun, T., 2009. Düşük Maliyetli Bazı Doğal Adsorbanlar Kullanılarak Ağır Metallerin Sulu Çözeltilerden Adsorpsiyonunun İncelenmesi. 
Selçuk Üniversitesi Fen Bilimleri Enstitüsü, Doktora Tezi, Konya.

30. Gübbük, İ.H., 2006. Tek Moleküllü Tabakaların Fonksiyonelleştirilmesi ve Uygulamaları. Selçuk Üniversitesi Fen Bilimleri Enstitüsü, Doktora Tezi, Konya.

31.Jung, C., Heo, J., Han, J., Her, N., Lee, S.-J., Oh, J., Ryu, J., Yoon, Y., 2013. Hexavalent Chromium Removal by Various Adsorbents: Powdered Activated Carbon, Chitosan and Single/multi-walled Carbon Nanotubes, Separation and Purification Technology, 106, 63-71.

32. Parlayıc1, S., Pehlivan, E., 2018. Chitosan Based a New Bio-Composite Adsorbent for the Removal of Cr (VI) from Aqueous Solution, Annals of Ecology and Environmental Science, 2(4), 30-35.

33. Li, L., Fan, L., Sun, M., Qiu, H., Li, X., Duan, H., Luo, C., 2013. Adsorbent for Chromium Removal Based on Graphene Oxide Functionalized with Magnetic CyclodextrinChitosan, Colloids and Surfaces B: Biointerfaces, 107, 76-83.

34. Selvi, K., Pattabhi, S., Kadirvelu, K., 2001. Removal of Cr (VI) from Aqueous Solution by Adsorption Onto Activated Carbon, Bioresource Technol, 80(1), 87-89.

35. Babel, S., Kurniawan, T.A., 2004. Cr(VI) Removal from Synthetic Wastewater Using Coconut Shell Charcoal and Commercial Activated Carbon Modified with Oxidizing Agents and/or Chitosan, Chemosphere, 54(7), 951-967.

36. Acharya, J., Sahu, J.N., Sahoo, B.K., Mohanty, C.R., Meikap, B.C., 2009. Removal of Chromium (VI) from Wastewater by Activated Carbon Developed from Tamarind Wood Activated with Zinc Chloride, Chem. Eng. J., 150(1), 25-39.

37. Mor, S., Ravindra, K., Bishnoi, N., 2007. Adsorption of Chromium from Aqueous Solution by Activated Alumina and Activated Charcoal, Bioresource Technol, 98(4), 954-957.

38. Farooq, U., Kozinski, J.A., Khan, M.A., Athar, M., 2010. Biosorption of Heavy Metal Ions Using Wheat Based Biosorbents-A Review of the Recent Literature, Bioresource Technol, 101(14), 5043-5053.

39. Karthikeyan, T., Rajgopal, S., Miranda, L.R., 2005. Chromium (VI) Adsorption from Aqueous Solution by Hevea Brasilinesis Sawdust Activated Carbon, J. Hazard Mater., 124(1-3), 192-199.

40. Li, Y.H., Di, Z.C., Ding, J., Wu, D.H., Luan, Z.K., Zhu, Y.Q., 2005. Adsorption Thermodynamic, Kinetic and Desorption Studies of $\mathrm{Pb}^{2+}$ on Carbon Nanotubes, Water Res., 39(4), 605-609.

41. Ajmal, M., Rao, R.A.K., Ahmad, R., Ahmad, J., 2000. Adsorption Studies on Citrus Reticulata (fruit peel of orange): Removal and Recovery of Ni(II) from Electroplating Wastewater, J. Hazard Mater., 79(1-2), 117-131.

42. Naiya, T.K., Chowdhury, P., Bhattacharya, A.K., Das, S.K., 2009. Saw Dust and Neem Bark as Low-cost Natural Biosorbent for Adsorptive Removal of $\mathrm{Zn}$ (II) and Cd(II) Ions from Aqueous Solutions, Chem. Eng. J., 148(1), 68-79. 
